\title{
Diet quality and hearing loss among middle-older aged adults in the USA: findings from National Health and Nutrition Examination Survey
}

\author{
Qiushi Huang ${ }^{1,2}$, Yichen Jin², Nicholas S Reed ${ }^{3,4}$, Yan Ma ${ }^{5}$, Melinda C Power ${ }^{1}$ and \\ Sameera A Talegawkar ${ }^{1,2, *}$ \\ 'Department of Epidemiology and Biostatistics, Milken Institute School of Public Health, The George Washington \\ University, Washington, DC, USA: ${ }^{2}$ Department of Exercise and Nutrition Sciences, Milken Institute School of Public \\ Health, The George Washington University, 950 New Hampshire Ave. NW, Washington, DC 20052, USA: \\ ${ }^{3}$ Department of Otolaryngology-Head and Neck Surgery, Johns Hopkins School of Medicine, Baltimore, MD, USA: \\ ${ }^{4}$ Cochlear Center for Hearing and Public Health, Johns Hopkins University Bloomberg School of Public Health, \\ Baltimore, MD, USA: ${ }^{5}$ Department of Biostatistics and Bioinformatics, Milken Institute School of Public Health, The \\ George Washington University, Washington, DC, USA
}

Submitted 30 January 2019: Final revision received 21 June 2019: Accepted 2 July 2019: First published online 31 0ctober 2019

\begin{abstract}
Objective: To examine the associations between overall diet quality and hearing function among middle-older aged adults in the USA.

Design: Cross-sectional analysis. Diet quality was examined using the Mediterranean Diet Score (MDS), using data from a single $24 \mathrm{~h}$ dietary recall. Hearing function was objectively measured by audiometry assessments and hearing loss, including high- and low-frequency hearing loss, was defined as pure-tone averages at specific ranges of hearing frequencies $>25 \mathrm{~dB}$. Weighted logistic regression analyses were performed to examine the associations of MDS (scored $0-9$, categorized at the median as $\leq 3$ or $>3$ ) with hearing loss and high- and low-frequency hearing loss.

Setting: National Health and Nutrition Examination Surveys 2000-2006 and 2009-2012.

Participants: Adults aged $\geq 50$ years ( $n$ 1639) with valid dietary and audiometry assessments.

Results: After adjusting for potential confounders, a non-significant trend for a protective association of higher MDS was observed for hearing loss ( OR $=0.78$; $95 \%$ CI $0.49,1.23)$. A significant inverse association was observed for highfrequency hearing loss (OR $=0.64 ; 95 \%$ CI 0.43, 0.95). No association was found for low-frequency hearing loss among women; however, higher MDS was significantly associated with higher odds of low-frequency hearing loss among men (OR $=2 \cdot 63$; $95 \%$ CI 1.39, 4.95).

Conclusions: Among middle-older aged adults, adherence to a Mediterraneanstyle diet was inversely associated with hearing loss, including those at high hearing frequencies, among older adults. However, a detrimental association was observed at low hearing frequencies among men. Future investigations with a longitudinal design are needed to clarify the associations between diet quality and hearing loss.
\end{abstract}

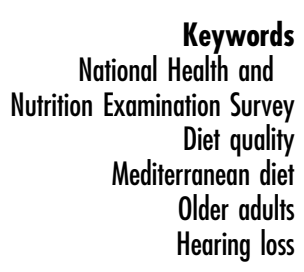

Once viewed as a typical, non-consequential aspect of ageing, hearing loss is an emerging public health concern that affects nearly 38 million individuals aged 12 years or older in the USA ${ }^{(1)}$ and its prevalence is projected to continue increasing because of the ageing of society ${ }^{(2)}$. Prevalence of hearing loss increases with age such that among adults over 50 years of age, approximately $26 \cdot 2$ million have bilateral hearing loss ${ }^{(3)}$. Hearing loss is associated with significant economic costs and negative health outcomes, including poverty ${ }^{(4)}$, early retirement ${ }^{(5)}$ and use of sickness 
benefits or disability pension ${ }^{(6)}$, resulting in significant societal economic impacts. Moreover, individuals with hearing loss are at higher risk for dementia ${ }^{(7)}$, poor physical functioning $^{(8)}$, social isolation ${ }^{(9)}$ and a lower quality of life ${ }^{(10)}$. Given these important outcomes, it is essential to elucidate protective factors of hearing loss in order to identify effective modes of prevention.

Hearing loss is multifactorial. Studies have identified several risk factors for hearing loss including sociodemographic characteristics such as older age, male sex and non-Hispanic White ethnicity ${ }^{(11)}$; genetic factors ${ }^{(12)}$; exposure to noise and ototoxic drugs ${ }^{(11,13)}$; and vascular factors including diabetes, hypertension, smoking and obesity ${ }^{(14)}$. While several of the risk factors including age, sex, ethnicity and genetics are non-modifiable, other lifestyle-related factors are, making their study crucial. One such modifiable factor is diet. A healthy diet rich in many nutrients may be protective against hearing loss by several mechanisms including regulating oxidative stress, protecting cochlear blood flow, and reducing neuroinflammation and neurodegeneration of auditory nerve fibres and central auditory pathways ${ }^{(15,16)}$. However, limited data are available on the role of dietary patterns in hearing loss.

Previous epidemiological investigations demonstrating associations between diet and hearing loss have relied upon single nutrient measurements and have shown protective effect for $\beta$-carotene, $\beta$-cryptoxanthin, folate, vitamin $\mathrm{C}$, $\mathrm{Mg}$ and $n-3$ fatty acid intakes ${ }^{(17-20)}$. However, the single nutrient approach is limited given the complexity of diets and the possible interactions between dietary constituents. Among overall diet analyses, the Healthy Eating Index (HEI), the 2010 Alternative Healthy Eating Index (AHEI2010) and the Dietary Approaches to Stop Hypertension (DASH) score have been shown to be associated with better hearing at high frequencies ${ }^{(21)}$ and lower risk of moderate or worse hearing loss ${ }^{(22)}$. Notably, adherence to a Mediterranean-style diet was examined longitudinally in the Nurses' Health Study II (NHS II) and investigators found that better adherence to the Alternate Mediterranean diet (AMED) was protective against moderate or worse hearing loss among women ${ }^{(22)}$, but these analyses are limited by their reliance on self-reported hearing ${ }^{(23)}$.

There is a need for research investigating the association between dietary patterns, a broader and more accurate picture of food intake and overall diet, and the risk of objectively measured hearing loss to provide informative and simplified public health recommendations and interpretations ${ }^{(24)}$. Moreover, a higher adherence to a Mediterranean-style diet has been reported to be beneficial for preventing multiple age-related chronic conditions and functional declines that have also been shown to be associated with hearing function ${ }^{(7,8,25)}$. Therefore, the objectives of the present analyses were to examine the associations between adherence to a Mediterranean-style diet in adults aged 50 years or older with hearing loss assessed by pure-tone audiometry. Pure-tone audiometry is an objective measure and is the gold standard for measuring hearing loss ${ }^{(26)}$. Loss of hearing function among older adults usually starts at higher frequencies and progresses to lower frequencies, and individuals with high-frequency hearing loss have difficulty understanding speech and language, especially in noisy environments ${ }^{(27)}$. Therefore, we also assessed the associations of a Mediterranean-style diet with high- and low-frequency hearing loss separately, which may be more informative, as the high frequency regions in the cochlea are more susceptible to metabolic damage compared with the low frequency regions ${ }^{(28)}$.

\section{Methods}

\section{Study population}

The National Health and Nutrition Examination Survey (NHANES) is a series of cross-sectional surveys. Every 2 years, a random sample of approximately 10000 individuals is selected to represent the civilian, non-institutionalized US population. The detailed sampling methods have been explained elsewhere ${ }^{(29)}$. Among the NHANES cycles between 2001 and 2012, auditory data were available among adults of NHANES cycles 2001-2006 and 2009-2012. Among all NHANES participants in 2001-2006 and 2009-2012 cycles, there were 13020 participants aged 50 years or older. Of them, 8759 were excluded due to incomplete or missing auditory data, and an additional 159 were excluded due to incomplete dietary data. Other exclusion criteria included: hearing-related medical conditions including ear tubes, abnormal otoscopy, impacted cerumen and abnormal tympanometry (peak pressure $\leq-150 \mathrm{daPa}$; compliance $\leq 0.3 \mathrm{ml}$ ) at either ear ( $n 1633$ excluded); more than $10 \mathrm{~dB}$ difference between test and retest thresholds at $1 \mathrm{kHz}$ ( $n 1$ excluded); and more than $15 \mathrm{~dB}$ difference between ears on either low- or high-frequency pure-tone average ( $n 334$ excluded). We further excluded 495 participants who had missing data on any of the covariates included in the analysis. This left a final sample size of 1639 participants eligible for the reported analyses.

\section{Mediterranean Diet Score}

Dietary assessment in the NHANES is conducted using $24 \mathrm{~h}$ dietary recalls in a mobile examination centre. In the 2001-2002 cycle, only one dietary recall was collected for all participants. In the 2003-2006 and 2009-2012 cycles, two dietary recalls were collected for all participants; data from the first dietary recall were included in our analysis to maximize sample size. The food group data were obtained from the US Department of Agriculture MyPyramid Equivalents Database (MPED) versions 1.0 and 2.0, and the Food Pattern Equivalents Database (FPED) 2005-2006, 2009-2010 and 2011-2012.

The Mediterranean Diet Score (MDS) is a measure of adherence to a Mediterranean-style dietary pattern ${ }^{(30)}$. The 10-point MDS is composed of nine items: vegetables, 
fruits and nuts, legumes, whole grains, meat, fish, dairy, alcohol and ratio of monounsaturated to saturated fat (MUFA:SFA). The intakes of these nine food items were dichotomized using sex-specific median values as a cutoff. A score of 1 was assigned for consumption above the median level of presumed beneficial foods, which included vegetables, fruits and nuts, legumes, whole grains, fish and MUFA:SFA. A score of 1 was also assigned for consumption below the sex-specific median level of presumed detrimental foods which included meat and dairy products. Otherwise no points were given. For alcohol, 1 point was assigned to men who consumed between 10 and $50 \mathrm{~g}$ ethanol/d and to women who consumed between 5 and $25 \mathrm{~g}$ ethanol/d $v$. a score of 0 . Thus, the total MDS ranged from 0 (minimal adherence to the traditional Mediterranean diet) to 9 (maximal adherence). The distribution of the MDS was examined and less than $4 \%$ of the analytical population had an MDS $>6$. Since there are no established cut-offs for the MDS, the MDS was dichotomized at the median as MDS $>3$ or MDS $\leq 3$ for the present analyses.

\section{Audiometric testing}

The audiometry examination was performed in a soundisolating booth located in a dedicated room in the mobile examination centre by health technicians professionally trained by a certified audiologist from the National Institute for Occupational Safety and Health. The pure-tone air conduction hearing tests were conducted at seven frequencies $(0.5,1,2,3,4,6$ and $8 \mathrm{kHz})$ for both ears. The instruments used included an Interacoustics model AD226 audiometer with standard TDH-39/49 headphones and Etymotic EarTone $3 \mathrm{~A}$ insert earphones ${ }^{(31)}$.

Pure-tone averages (PTA) were then calculated for speech (Speech-PTA: 0.5, 1, 2 and $4 \mathrm{kHz}$ ), high (HFPTA: 3, 4, 6 and $8 \mathrm{kHz}$ ) and low frequencies (LFPTA: 0.5, 1 and $2 \mathrm{kHz}$ ). The average PTA on both ears were used for analysis. Hearing loss was defined as a SpeechPTA $>25 \mathrm{~dB}$ according to the WHO classification ${ }^{(32)}$ and also categorized as: normal (Speech-PTA $\leq 25 \mathrm{~dB}$ ), mild loss $(25 \mathrm{~dB}<$ Speech-PTA $\leq 40 \mathrm{~dB})$ and moderate/severe loss (Speech-PTA $>40 \mathrm{~dB}$ ). High-frequency hearing loss was defined as a HFPTA $>25 \mathrm{~dB}$. Low-frequency hearing loss was defined as a LFPTA $>25 \mathrm{~dB}$.

\section{Covariates}

Covariates were selected based on univariate analysis and from previous literature. Data on potential confounders were obtained from standard questionnaires and physical examinations. Age (years), sex, race/ethnicity (nonHispanic White, non-Hispanic Black, Hispanic and Other), education (high school or less; some college; college graduate) and veteran status were self-reported on the demographic questionnaire. Socio-economic status was assessed by a ratio of family income to poverty guidelines. Current smoking status was self-reported on the smoking and tobacco use questionnaire. BMI was computed using measured data from the physical examination and categorized as $<25 \mathrm{~kg} / \mathrm{m}^{2}, 25-29.9 \mathrm{~kg} / \mathrm{m}^{2}$ and $\geq 30 \mathrm{~kg} / \mathrm{m}^{2}$. Total energy intake $(\mathrm{kcal} / \mathrm{d})$ was estimated from dietary recall data. Physical activity level (vigorous; moderate; no vigorous or moderate) was categorized using self-reported vigorous and moderate activities. Presence of chronic health conditions including diabetes, hypertension and high lipid levels was based on self-reported diagnosis on any of the conditions. Information on exposure to noise including firearm use, occupational or recreational noise was based on self-reported exposure to any of the noise sources.

\section{Statistical analysis}

NHANES complex survey weights of the first dietary recall were used to account for the sampling design. All analyses incorporated the 10-year dietary survey weights for the 2001-2006 and 2009-2012 cycles. In our primary analysis, multivariable logistic regression models were used to examine the association of MDS with hearing loss, high-frequency hearing loss and low-frequency hearing loss. Multinomial logistic regression was used to examine the association between MDS and hearing loss levels, and associations of MDS with Speech-PTA, HFPTA and LFPTA on the continuous scale were assessed using multivariable linear regression in model 1 , which was adjusted for age, sex and total energy intake, and model 2, which was adjusted for covariates in model 1 and additional variables including sociodemographic characteristics (race/ ethnicity, education, family income to poverty ratio), clinical factors (BMI, physical activity, current smoking status, presence of health conditions) and hearing-related exposures (noise exposure, veteran status). We first examined heterogeneity by age and sex using a Wald test of the interaction term between age, sex and MDS. After identifying a statistically significant interaction $(P<0.05)$ between sex and MDS in low-frequency hearing loss, the analysis was then stratified by sex to examine the effect of MDS on low-frequency hearing loss in men and women separately. For all other models with statistically insignificant interaction effects, the interaction term was not included in the final models presented. A sensitivity analysis was conducted to assess the associations between MDS and hearing loss, high-frequency and low-frequency hearing loss by age decades. To further explore which food group(s) were responsible for the association between MDS and lowfrequency hearing loss in men (associations for women were not significant and were therefore not examined further), additional analyses were conducted with each food group in the Mediterranean diet as the independent variable, and adjusted for the MDS without the food group being modelled. The Wald tests were performed for all models and statistical significance was considered to be present at $P<0.05$. All analyses were performed using the statistical software package SAS version 9.4 . 
Table 1 Sociodemographic and health characteristics of participants aged 50 years or older from the National Health and Nutrition Examination Surveys 2000-2006 and 2009-2012, overall and by hearing status

\begin{tabular}{|c|c|c|c|c|c|c|c|}
\hline & \multicolumn{2}{|c|}{ Total $(n 1639)$} & \multicolumn{2}{|c|}{$\begin{array}{l}\text { Hearing loss } † \\
\quad(n 545)\end{array}$} & \multicolumn{2}{|c|}{$\begin{array}{l}\text { Normal hearing } \\
\quad(n 1094)\end{array}$} & \multirow[b]{2}{*}{$P$ value } \\
\hline & Mean or $\%$ & SD & Mean or \% & SD & Mean or \% & SD & \\
\hline Age (years) & $61 \cdot 8$ & 0.4 & $68 \cdot 8$ & 0.9 & $59 \cdot 1$ & 0.3 & $<0.0001$ \\
\hline \multicolumn{8}{|l|}{ Mediterranean Diet Score } \\
\hline$\leq 3$ & $52 \cdot 0$ & - & $55 \cdot 3$ & - & $50 \cdot 7$ & - & \multirow[t]{2}{*}{0.2804} \\
\hline$>3$ & $48 \cdot 0$ & - & $44 \cdot 7$ & - & $49 \cdot 3$ & - & \\
\hline \multicolumn{8}{|l|}{ Sex } \\
\hline Men & $42 \cdot 6$ & - & 51.6 & - & $39 \cdot 0$ & - & \multirow{2}{*}{0.0119} \\
\hline Women & $57 \cdot 4$ & - & $48 \cdot 4$ & - & $61 \cdot 0$ & - & \\
\hline \multicolumn{8}{|l|}{ Race } \\
\hline Non-Hispanic White & $78 \cdot 8$ & - & 83.4 & - & $76 \cdot 9$ & - & \multirow[t]{4}{*}{0.0710} \\
\hline Non-Hispanic Black & 9.5 & - & $6 \cdot 3$ & - & $10 \cdot 8$ & - & \\
\hline Hispanic & $7 \cdot 3$ & - & $5 \cdot 8$ & - & 7.9 & - & \\
\hline Other & 4.4 & - & 4.4 & - & 4.3 & - & \\
\hline \multicolumn{8}{|l|}{ Education } \\
\hline High school or less & $39 \cdot 2$ & - & $54 \cdot 0$ & - & 33.4 & - & \multirow[t]{3}{*}{$<0.0001$} \\
\hline Some college & $29 \cdot 3$ & - & 28.4 & - & $29 \cdot 7$ & - & \\
\hline College graduate & 31.5 & - & $17 \cdot 6$ & - & $36 \cdot 9$ & - & \\
\hline Family income to poverty ratio & 3.3 & 0.1 & 2.9 & 0.1 & 3.4 & 0.1 & $<0.0001$ \\
\hline \multicolumn{8}{|l|}{ Physical activity level } \\
\hline Vigorous & $18 \cdot 0$ & - & $10 \cdot 8$ & - & $20 \cdot 8$ & - & \multirow[t]{3}{*}{0.0014} \\
\hline Moderate & $35 \cdot 2$ & - & $32 \cdot 4$ & - & $36 \cdot 3$ & - & \\
\hline No vigorous or moderate & $46 \cdot 8$ & - & 56.9 & - & 42.9 & - & \\
\hline \multicolumn{8}{|l|}{ BMI $\left(\mathrm{kg} / \mathrm{m}^{2}\right)$} \\
\hline$<25$ & $26 \cdot 8$ & - & $28 \cdot 0$ & - & $26 \cdot 3$ & - & \multirow[t]{3}{*}{0.7002} \\
\hline $25-29 \cdot 9$ & $36 \cdot 4$ & - & $37 \cdot 4$ & - & $36 \cdot 1$ & - & \\
\hline$\geq 30$ & $36 \cdot 8$ & - & 34.6 & - & $37 \cdot 6$ & - & \\
\hline Current smoking status, yes & $17 \cdot 5$ & - & 13.5 & - & $19 \cdot 0$ & - & 0.1499 \\
\hline $\begin{array}{l}\text { Chronic health conditions (hypertension, } \\
\text { high cholesterol, diabetes), yes }\end{array}$ & $70 \cdot 1$ & - & $75 \cdot 4$ & - & $68 \cdot 1$ & - & 0.0148 \\
\hline $\begin{array}{l}\text { Noise exposure (recreational, firearm or } \\
\text { occupational), yes }\end{array}$ & $51 \cdot 8$ & - & $58 \cdot 2$ & - & $49 \cdot 3$ & - & 0.0441 \\
\hline Veteran status, yes & $16 \cdot 1$ & - & $25 \cdot 0$ & - & $12 \cdot 6$ & - & $<0.0001$ \\
\hline
\end{tabular}

†Hearing loss was defined as a pure-tone average at speech frequencies $(0 \cdot 5,1,2$ and $4 \mathrm{kHz})>25 \mathrm{~dB}$.

\section{Results}

Baseline characteristics of the analytic sample by hearing loss status are described in Table 1 . Overall, 33.2\% of the participants had hearing loss. Compared with those without hearing loss, participants with hearing loss were older, more likely to be men, with an education level of high school or less, have a lower family income to poverty ratio, be physically inactive, report one or more chronic health conditions (hypertension, high cholesterol or diabetes), report exposure to excess noise and have served in the military ( $P$ values for group comparisons $<0.05$ ).

The associations between MDS and hearing loss are shown in Table 2. After adjustment for age, sex and total energy intake, there was a trend for an inverse association between MDS and hearing loss (OR $=0.68$; $95 \%$ CI 0.46, $1 \cdot 01)$, but the association was not statistically significant. In model 2 that adjusted for additional potential confounders, a similar non-significant trend was observed (OR $=0.78$; $95 \%$ CI 0.49, 1.23). Furthermore, no significant results were seen for associations between MDS and hearing loss levels (data not shown).

Table 3 shows the association between MDS and highfrequency hearing loss. Of the 1639 participants, 1067 had high-frequency hearing loss. When comparing participants with high MDS (>3) with those with low MDS ( $\leq 3)$, the odds of high-frequency hearing loss decreased significantly in both the model adjusted for age, sex and total energy intake (OR $=0.56 ; 95 \% \mathrm{CI} 0.38,0.81)$ and the fully adjusted model (OR $=0.64 ; 95 \%$ CI 0.43, 0.95).

There was an interaction by sex for the association between MDS and low-frequency hearing loss, and therefore we stratified our analyses by sex. Among women ( $n$ 884), there was a trend for a protective association between MDS and low-frequency hearing loss which was not statistically significant (Table 4). Interestingly, men $(n 755)$ with higher MDS were more likely to report low-frequency hearing loss (age-, sex- and total energy intake-adjusted model: $\mathrm{OR}=2 \cdot 24 ; 95 \% \mathrm{CI} 1.28,3.92)$ and the magnitude of the association was even greater after adjusting for other confounders (fully adjusted model: OR $=2 \cdot 63$; $95 \%$ CI 1.39, 4.95; Table 4).

For analysis on Speech-PTA, HFPTA and LFPTA on the continuous scale, higher MDS was found to be significantly associated with lower Speech-PTA and HFPTA in the model adjusted for age, sex and energy, but only HFPTA showed a significant inverse association with MDS in the fully adjusted model (see online supplementary material, 
Table 2 Associations between Mediterranean Diet Score and hearing loss $\nmid$ using multivariable logistic regression models among participants aged 50 years or older from the National Health and Nutrition Examination Surveys 2000-2006 and 2009-2012 (n 1639)

\begin{tabular}{|c|c|c|c|c|}
\hline \multirow[b]{2}{*}{ Independent variable } & \multicolumn{2}{|c|}{ Model $1 \mp$} & \multicolumn{2}{|c|}{ Model $2 \S$} \\
\hline & OR & $95 \% \mathrm{Cl}$ & OR & $95 \% \mathrm{Cl}$ \\
\hline \multicolumn{5}{|l|}{ Mediterranean Diet Score } \\
\hline$\leq 3$ (reference) & 1.00 & - & 1.00 & - \\
\hline$>3$ & 0.68 & $0.46,1.01$ & 0.78 & $0.49,1.23$ \\
\hline Age (years) & $1 \cdot 15^{\star \star \star}$ & $1 \cdot 12,1 \cdot 17$ & $1 \cdot 14^{\star \star \star}$ & $1.11,1.17$ \\
\hline \multicolumn{5}{|l|}{ Sex } \\
\hline Men (reference) & 1.00 & - & 1.00 & - \\
\hline Women & $0.34^{\star \star \star}$ & $0.24,0.59$ & $0.38^{\star \star}$ & $0.20,0.72$ \\
\hline Total energy intake (kcal) & 1.00 & $1.00,1.00$ & 1.00 & $1.00,1.00$ \\
\hline \multicolumn{5}{|l|}{ Race } \\
\hline Non-Hispanic White (reference) & - & - & 1.00 & - \\
\hline Non-Hispanic Black & - & - & $0.41^{\star \star *}$ & $0.26,0.64$ \\
\hline Hispanic & - & - & 0.68 & $0.38,1 \cdot 21$ \\
\hline Other & - & - & 1.23 & $0.42,3.63$ \\
\hline \multicolumn{5}{|l|}{ Education } \\
\hline High school or less (reference) & - & - & 1.00 & - \\
\hline Some college & - & - & 0.74 & $0.46,1.19$ \\
\hline College graduate & - & - & $0.39^{\star * \star}$ & $0.25,0.61$ \\
\hline Family income to poverty ratio & - & - & 0.98 & $0.88,1 \cdot 10$ \\
\hline \multicolumn{5}{|l|}{ Physical activity level } \\
\hline No moderate or vigorous (reference) & - & - & 1.00 & - \\
\hline Moderate & - & - & 0.86 & $0.50,1.47$ \\
\hline Vigorous & - & - & 0.78 & $0.42,1.45$ \\
\hline \multicolumn{5}{|l|}{ BMI $\left(\mathrm{kg} / \mathrm{m}^{2}\right)$} \\
\hline$<25$ (reference) & - & - & 1.00 & - \\
\hline $25-29.9$ & - & - & 0.98 & $0.57,1.69$ \\
\hline$\geq 30$ & - & - & 0.96 & $0.61,1.50$ \\
\hline Current smoking status & - & - & 1.09 & $0.52,2.29$ \\
\hline $\begin{array}{l}\text { Chronic health conditions (hypertension, } \\
\text { high cholesterol, diabetes) }\end{array}$ & - & - & 0.83 & $0.56,1.23$ \\
\hline $\begin{array}{l}\text { Noise exposure (recreational, } \\
\text { firearm and occupational) }\end{array}$ & - & - & $1 \cdot 29$ & $0.81,2.07$ \\
\hline Veteran status & - & - & 0.88 & $0.54,1.43$ \\
\hline
\end{tabular}

${ }^{* \star} P<0.01,{ }^{* \star *} P<0.001$.

†Hearing loss was defined as a pure-tone average at speech frequencies $(0.5,1,2$ and $4 \mathrm{kHz})>25 \mathrm{~dB}$.

$\ddagger$ Adjusted for age, sex and total energy intake.

§Further adjusted for race, education, family income to poverty ratio, physical activity level, BMI, current smoking status, chronic health conditions, noise exposure and veteran status.

Supplemental Table S1). No significant associations were found for LFPTA.

Sensitivity analyses stratified by age group (50-59, 60-69 and $\geq 70$ years) revealed that the association between MDS (>3v. $\leq 3)$ and hearing loss was stronger at younger age (50-59 years: $\mathrm{OR}=0.42 ; 95 \%$ CI 0.20 , $0 \cdot 88$; see online supplementary material, Supplemental Table S2). The positive association between MDS and low-frequency hearing loss was the strongest among men aged 60-69 years (Supplemental Table S3). Further analysis on the effect of each food item in the Mediterranean diet showed that high MUFA:SFA and low intake of dairy were associated with higher odds of lowfrequency hearing loss among men (Supplemental Table S4).

Differences in sociodemographic characteristics between individuals included in and excluded from the study are shown in the online supplementary material, Supplemental Table S5. Individuals included in the analysis were younger, had higher level of education and socioeconomic status, were more physically active, had higher BMI and had higher exposure to noise.

\section{Discussion}

In the present study, $33.2 \%$ of the adults aged 50 years or older had hearing loss. Higher adherence to a Mediterranean-style diet measured using the MDS was not associated with hearing. However, we found a protective association between higher adherence to a Mediterranean-style diet and high-frequency hearing loss. While no associations were observed for women, MDS was positively associated with low-frequency hearing loss among men.

The protective effect of overall diet quality on hearing functions, including those at high hearing frequencies, among older adults observed in the current study is consistent with most previous investigations. In a study examining the associations of diet with hearing status among participants aged 60-69 years in the 1999-2002 cycles of NHANES, better diet quality as measured by HEI was associated with better hearing at high frequencies. A similar trend was observed among participants aged 50-59 years, but the association was not statistically 
Diet quality and hearing loss

Table 3 Associations between Mediterranean Diet Score and high-frequency hearing loss $\dagger$ using multivariable logistic regression models among participants aged 50 years or older from the National Health and Nutrition Examination Surveys 2000-2006 and 2009-2012 ( $n$ 1639)

\begin{tabular}{|c|c|c|c|c|}
\hline \multirow[b]{2}{*}{ Independent variable } & \multicolumn{2}{|c|}{ Model 1‡ } & \multicolumn{2}{|c|}{ Model $2 \S$} \\
\hline & OR & $95 \% \mathrm{Cl}$ & OR & $95 \% \mathrm{Cl}$ \\
\hline \multicolumn{5}{|l|}{ Mediterranean Diet Score } \\
\hline$\leq 3$ (reference) & 1.00 & - & 1.00 & - \\
\hline$>3$ & $0.56^{\star}$ & $0.38,0.81$ & $0.64^{*}$ & $0.43,0.95$ \\
\hline Age (years) & $1 \cdot 15^{\star \star \star}$ & $1 \cdot 12,1 \cdot 19$ & $1 \cdot 15^{\star \star \star}$ & $1.11,1.19$ \\
\hline \multicolumn{5}{|l|}{ Sex } \\
\hline Men (reference) & 1.00 & - & 1.00 & - \\
\hline Women & $0 \cdot 19^{\star \star \star}$ & $0.11,0.31$ & $0 \cdot 19^{\star \star \star}$ & $0.12,0.31$ \\
\hline Total energy intake (kcal) & 1.00 & $1.00,1.00$ & 1.00 & $1.00,1.00$ \\
\hline \multicolumn{5}{|l|}{ Race } \\
\hline Non-Hispanic White (reference) & - & - & 1.00 & - \\
\hline Non-Hispanic Black & - & - & $0.46^{\star \star \star}$ & $0.31,0.68$ \\
\hline Hispanic & - & - & 0.61 & $0.35,1.05$ \\
\hline Other & - & - & 1.58 & $0.88,2.83$ \\
\hline \multicolumn{5}{|l|}{ Education } \\
\hline High school or less (reference) & - & - & 1.00 & - \\
\hline Some college & - & - & 0.76 & $0.47,1.23$ \\
\hline College graduate & - & - & 0.68 & $0.41,1.12$ \\
\hline Family income to poverty ratio & - & - & 0.94 & $0.82,1.07$ \\
\hline \multicolumn{5}{|l|}{ Physical activity level } \\
\hline No moderate or vigorous (reference) & - & - & 1.00 & - \\
\hline Moderate & - & - & 0.69 & $0.41,1.15$ \\
\hline Vigorous & - & - & 0.54 & $0.28,1.02$ \\
\hline \multicolumn{5}{|l|}{ BMI $\left(\mathrm{kg} / \mathrm{m}^{2}\right)$} \\
\hline$<25$ (reference) & - & - & 1.00 & - \\
\hline $25-29.9$ & - & - & $0.60^{*}$ & $0.41,0.90$ \\
\hline$\geq 30$ & - & - & 0.68 & $0.42,1.11$ \\
\hline Current smoking status & - & - & $1.59^{*}$ & $1.09,2.32$ \\
\hline $\begin{array}{l}\text { Chronic health conditions (hypertension, } \\
\text { high cholesterol, diabetes) }\end{array}$ & - & - & 1.02 & $0.72,1.46$ \\
\hline $\begin{array}{l}\text { Noise exposure (recreational, } \\
\text { firearm and occupational) }\end{array}$ & - & - & $1 \cdot 38$ & $0 \cdot 88,2 \cdot 16$ \\
\hline Veteran status & - & - & $1 \cdot 12$ & $0.59,2.09$ \\
\hline
\end{tabular}

${ }^{\star} P<0.05,{ }^{\star \star *} P<0.001$.

†High-frequency hearing loss was defined as a pure-tone average at high frequencies $(3,4,6$ and $8 \mathrm{kHz})>25 \mathrm{~dB}$.

$\ddagger$ Adjusted for age, sex and total energy intake.

$\S$ Further adjusted for race, education, family income to poverty ratio, physical activity level, BMI, current smoking status, chronic health conditions, noise exposure and veteran status.

significant ${ }^{(21)}$. Results from the age-stratified analyses in the longitudinal NHS II study also suggested a protective effect of better overall diet quality as measured by AMED and DASH diet scores against the risk of hearing loss among women aged 50-59 years and $\geq 60$ years $^{(22)}$. Additionally, a significant inverse association was observed between diet quality as measured by AHEI-2010 and the risk of hearing loss ${ }^{(22)}$. An Australian study consisting of adults aged 50 years or older reported that total diet score was inversely related to reporting of concurrent vision and hearing loss in a cross-sectional design; however, no significant effect of diet quality on development of vision and hearing loss was observed in the 5-year follow-up ${ }^{(33)}$. While a recent study of a European cohort has shown no significant associations between diet quality assessed by the Dutch Dietary Guidelines and hearing status in both low and high frequencies, dietary intake assessed by the FFQ in the study may result in larger recall bias ${ }^{(34)}$.

However, our study found a statistically significant positive association between MDS and low-frequency hearing loss among men, in contrast with the results from the other NHANES study examining the role of diet in low-frequency hearing loss ${ }^{(21)}$. It is possible that MUFA: SFA and dairy were correlated with other unknown risk factors that were associated with the risk of low-frequency hearing loss among men. This hypothesis, and the underlying mechanisms, require further investigation.

There are several hypothesized mechanisms by which specific nutrients in the Mediterranean diet may protect against hearing loss. Oxidative stress caused by build-up of free radicals in the inner ear leads to cell death and consequent vascular compromise and reduced cochlear blood flow ${ }^{(35)}$. Impaired homocysteine metabolism also contributes to inner-ear dysfunction and mediates vulnerability to age-related changes ${ }^{(36)}$. Many nutrients, such as $\beta$-carotene, vitamins $\mathrm{C}$ and $\mathrm{E}$ and folic acid, exhibit antioxidant capabilities and regulate redox stress by scavenging free radicals and maintaining antioxidant enzyme homeostasis ${ }^{(37,38)}$. In animal models, a high-fat diet rich in vitamin $\mathrm{E}$ and folic acid was associated with delayed age-related hearing loss progression ${ }^{(39)}$. Mg has also proven effective 
Table 4 Associations between Mediterranean Diet Score and low-frequency hearing loss $†$ using multivariable logistic regression models among participants aged 50 years or older from the National Health and Nutrition Examination Surveys 2000-2006 and 2009-2012, by $\operatorname{sex}(n 1639)$

\begin{tabular}{|c|c|c|c|c|c|c|c|c|}
\hline \multirow[b]{3}{*}{ Independent variable } & \multicolumn{4}{|c|}{ Men $(n 755)$} & \multicolumn{4}{|c|}{ Women $(n 884)$} \\
\hline & \multicolumn{2}{|c|}{ Model 1‡ } & \multicolumn{2}{|c|}{ Model $2 \S$} & \multicolumn{2}{|c|}{ Model 1‡ } & \multicolumn{2}{|c|}{ Model $2 \S$} \\
\hline & OR & $95 \% \mathrm{Cl}$ & OR & $95 \% \mathrm{Cl}$ & OR & $95 \% \mathrm{Cl}$ & OR & $95 \% \mathrm{Cl}$ \\
\hline \multicolumn{9}{|l|}{ Mediterranean Diet Score } \\
\hline$\leq 3$ (reference) & 1.00 & - & 1.00 & - & 1.00 & - & 1.00 & - \\
\hline$>3$ & $2 \cdot 24^{\star *}$ & $1 \cdot 28,3.92$ & $2 \cdot 63^{\star *}$ & $1.39,4.95$ & 0.60 & $0.38,1.06$ & 0.79 & $0.42,1.50$ \\
\hline Age (years) & $1 \cdot 15^{\star \star \star}$ & $1 \cdot 10,1 \cdot 19$ & $1 \cdot 14^{\star \star \star}$ & $1 \cdot 10,1 \cdot 19$ & $1 \cdot 14^{\star \star \star}$ & $1 \cdot 10,1 \cdot 15$ & $1 \cdot 14^{\star \star \star}$ & $1 \cdot 11,1 \cdot 18$ \\
\hline Total energy intake (kcal) & 1.00 & $1 \cdot 00,1 \cdot 00$ & 1.00 & $1 \cdot 00,1.00$ & 1.00 & $1.00,1.00$ & 1.00 & $1.00,1.00$ \\
\hline \multicolumn{9}{|l|}{ Race } \\
\hline Non-Hispanic White (reference) & - & - & 1.00 & - & - & - & 1.00 & - \\
\hline Non-Hispanic Black & - & - & $0.49^{*}$ & $0.25,0.97$ & - & - & 0.80 & $0.42,1.50$ \\
\hline Hispanic & - & - & 0.94 & $0.42,2 \cdot 10$ & - & - & $0.38^{\star *}$ & $0.21,0.70$ \\
\hline Other & - & - & 1.28 & $0.28,5.93$ & - & - & 0.57 & $0.22,1.43$ \\
\hline \multicolumn{9}{|l|}{ Education } \\
\hline High school or less (reference) & - & - & 1.00 & - & - & - & 1.00 & - \\
\hline Some college & - & - & $0.50^{*}$ & $0.27,0.91$ & - & - & 0.94 & $0.50,1.78$ \\
\hline College graduate & - & - & 0.59 & $0.24,1.44$ & - & - & $0.37^{\star}$ & $0.17,0.81$ \\
\hline Family income to poverty ratio & - & - & $0.78^{\star}$ & $0.62,0.99$ & - & - & 0.96 & $0.82,1 \cdot 13$ \\
\hline \multicolumn{9}{|l|}{ Physical activity level } \\
\hline No moderate or vigorous (reference) & - & - & 1.00 & - & - & - & 1.00 & - \\
\hline Moderate & - & - & 1.51 & $0 \cdot 81,2 \cdot 80$ & - & - & 0.66 & $0.30,1.45$ \\
\hline Vigorous & - & - & $1 \cdot 12$ & $0.52,2.46$ & - & - & 0.65 & $0.19,2.23$ \\
\hline \multicolumn{9}{|l|}{ BMI $\left(\mathrm{kg} / \mathrm{m}^{2}\right)$} \\
\hline$<25$ (reference) & - & - & 1.00 & - & - & - & 1.00 & - \\
\hline $25-29.9$ & - & - & 0.74 & $0.34,1.65$ & - & - & 1.22 & $0.60,2.48$ \\
\hline$\geq 30$ & - & - & $0 \cdot 81$ & $0.29,2.25$ & - & - & 0.85 & $0.46,1.56$ \\
\hline Current smoking status & - & - & 1.03 & $0.62,1.72$ & - & - & 1.08 & $0.44,2.70$ \\
\hline $\begin{array}{l}\text { Chronic health conditions } \\
\text { (hypertension, high cholesterol, diabetes) }\end{array}$ & - & - & 0.87 & $0.40,1.90$ & - & - & $0.51^{*}$ & $0.27,0.97$ \\
\hline $\begin{array}{l}\text { Noise exposure } \\
\text { (recreational, firearm and occupational) }\end{array}$ & - & - & $1 \cdot 83$ & $0.84,3.96$ & - & - & 1.65 & $0.82,3.35$ \\
\hline Veteran status & - & - & 0.90 & $0.48,1.69$ & - & - & 0.67 & $0.12,3.81$ \\
\hline
\end{tabular}

${ }^{\star} P<0.05,{ }^{* *} P<0.01,{ }^{* *} P<0.001$.

tLow-frequency hearing loss was defined as a pure-tone average at low frequencies $(0.5,1 \mathrm{and} 2 \mathrm{kHz})>25 \mathrm{~dB}$.

$\ddagger$ Adjusted for age and total energy intake.

§Further adjusted for race, education, family income to poverty ratio, physical activity level, BMI, current smoking status, chronic health conditions, noise exposure and veteran status.

in reducing noise-induced vasoconstriction and has been linked to reduced risk of hearing loss ${ }^{(35)}$. Dietary supplementation with $\beta$-carotene, vitamins $\mathrm{C}$ and $\mathrm{E}$ and $\mathrm{Mg}$ was protective against inner-ear cell death and corresponding permanent threshold shift ${ }^{(16)}$. Better adherence to a Mediterranean diet usually indicates increased consumption of fruits, vegetables, legumes, nuts and unrefined cereals, and these foods are rich in such vitamins and minerals that are beneficial for preventing hearing loss.

However, results from epidemiological studies on the association between single nutrients and foods with hearing loss are not consistent. Intakes of vitamins A and E were associated with hearing loss prevalence, but not incidence in Australia ${ }^{(40)}$. Folic acid was inversely associated with hearing loss among older adults in the Netherlands ${ }^{(19)}$ and among women in the USA ${ }^{(41)}$; however, no associations were found among older adults in Denmark ${ }^{(42)}$. While the protective effect of $\beta$-carotene against hearing loss was observed in the NHS II cohort ${ }^{(41)}$ and among NHANES 2001-2004 participants ${ }^{(17)}$, no relationships were observed among older adults in
$\operatorname{Japan}^{(43)}$, Australia ${ }^{(40)}$ and the USA ${ }^{(20)}$. Although vitamin $\mathrm{C}$ was associated with better hearing thresholds in NHANES $^{(17)}$, a detrimental effect of vitamin C intake has been reported in the NHS II study ${ }^{(41)}$. On the other hand, Mg intake has consistently been shown to be associated with better hearing function ${ }^{(44)}$. Furthermore, the joint protective effect between antioxidant vitamins and $\mathrm{Mg}$ against hearing loss was also demonstrated in NHANES ${ }^{(17)}$. Other studies also showed that higher intakes of dietary glycaemic load, fish and long-chain $n$-3 fatty acids were associated with reduced risk of hearing loss ${ }^{(18,45)}$.

In addition to the nutrients and minerals, phytochemicals, the bioactive non-nutrient compounds commonly found in plants, also exhibit antioxidant activities. As such, these compounds may have contributed to the observed inverse association between the risk of hearing loss and a diet that is rich in plant foods. Indeed, all dietary indices examined in the current and previous studies emphasize higher intakes of vegetables, fruits, whole grains, nuts and legumes, which are great sources of antioxidant 
compounds ${ }^{(30,46,47)}$. Furthermore, high-quality diets protect against vascular compromise and reduced cochlear blood flow by promoting beneficial blood lipid profiles, better endothelial function, lower blood pressure and less inflammation $^{(22)}$. Healthy diets may also reduce neuroinflammation and neurodegeneration of auditory nerve fibres and central auditory pathways ${ }^{(15,16,39)}$.

Our study has several strengths. In NHANES, hearing function has been measured using objectively measured audiometry assessments, considered a gold standard ${ }^{(26)}$. Dietary intakes were assessed using $24 \mathrm{~h}$ dietary recalls, which are considered to have less measurement error than FFQ, especially for estimates at the food group level ${ }^{(48)}$. Also, the effect of overall diet was estimated and used to account for the complex interactions and potential joint effects between foods and nutrients in a diet.

Our limitations include the inability to deduce causal inferences due to the cross-sectional nature of our analyses. The possibility of reverse causality, wherein loss of hearing function may have led to a loss of independence or income leading to a diet of poor quality, cannot be dismissed. While $24 \mathrm{~h}$ dietary recalls have less measurement error compared with other assessment methods and are good for estimating short-term dietary intakes, the measurement error in representing long-term diet is substantial. Additionally, our analyses showed that less than $4 \%$ of the sample population had MDS > 6, suggesting that the MDS may not accurately reflect the dietary habits of the US population. Therefore, diet quality as assessed by adherence to a modified Mediterranean-style diet that is applicable to the US population, such as the US Department of Agriculture Healthy Mediterranean-style Pattern ${ }^{(49)}$, may be more informative on the association between Mediterranean diet and hearing loss in the USA. While the NHANES has collected data on several covariates and confounders and these were adjusted for in our analyses, some residual confounding may be present due to the observational nature of NHANES. Also, we were unable to exclude individuals reporting conductive hearing loss, which is a potential confounder, since there were no data in the NHANES to indicate this. Furthermore, although the present analyses utilized the NHANES data, our analytical population may not be nationally representative due to the large proportion of NHANES participants excluded from the analyses. Additional analysis indicated significant differences in sociodemographic and health characteristics between participants who were included and excluded from the analysis. Therefore, our results may not be generalizable to the US population.

In summary, among adults aged 50 years or older, a higher adherence to a Mediterranean-style diet was associated with lower odds of hearing loss, including those at high hearing frequencies. Our findings with low-frequency hearing loss in men require further investigation. Studies with a longitudinal design are needed to confirm these findings.

\section{Acknowledgements}

Financial support: This research received no specific grant from any funding agency in the public, commercial or not-for-profit sectors. Conflict of interest: None. Authorship: Q.H. and Y.J. performed the data analysis. Q.H. drafted the manuscript, with supervision by S.A.T. Y.J., N.S.R., Y.M. and M.C.P. provided critical revisions to the manuscript. S.A.T. designed the research and had primary responsibility for the final content; and all authors read and approved the final manuscript. Ethics of human subject participation: Not applicable.

\section{Supplementary material}

To view supplementary material for this article, please visit https://doi.org/10.1017/S1368980019002970

\section{References}

1. Goman AM \& Lin FR (2016) Prevalence of hearing loss by severity in the United States. Am J Public Health 106, 1820-1822.

2. Goman AM, Reed NS \& Lin FR (2017) Addressing estimated hearing loss in adults in 2060. JAMA Otolaryngol Head Neck Surg 143, 733-734.

3. Lin FR, Niparko JK \& Ferrucci L (2011) Hearing loss prevalence in the United States. Arch Intern Med 171, 1851-1852.

4. Callander EJ, Schofield DJ \& Shrestha RN (2013) Chronic health conditions and poverty: a cross-sectional study using a multidimensional poverty measure. BMJ Open 3, e003397.

5. Helvik AS, Krokstad S \& Tambs K (2013) Hearing loss and risk of early retirement. The HUNT study. Eur J Public Health 23, 617-622.

6. Pierre PV, Fridberger A, Wikman A et al. (2012) Self-reported hearing difficulties, main income sources, and socioeconomic status; a cross-sectional population-based study in Sweden. BMC Public Health 12, 874.

7. Lin FR, Metter EJ, O'Brien RJ et al. (2011) Hearing loss and incident dementia. Arch Neurol 68, 214-220.

8. Chen DS, Betz J, Yaffe K et al. (2015) Association of hearing impairment with declines in physical functioning and the risk of disability in older adults. J Gerontol A Biol Sci Med Sci 70, 654-661.

9. Mick P, Kawachi I \& Lin FR (2014) The association between hearing loss and social isolation in older adults. Otolaryngol Head Neck Surg 150, 378-384.

10. Gopinath B, Schneider J, McMahon CM et al. (2012) Severity of age-related hearing loss is associated with impaired activities of daily living. Age Ageing 41, 195-200.

11. Hoffman HJ, Dobie RA, Losonczy KG et al. (2017) Declining prevalence of hearing loss in US adults aged 20 to 69 years. JAMA Otolaryngol Head Neck Surg 143, 274-285.

12. Uchida Y, Sugiura S, Sone M et al. (2014) Progress and prospects in human genetic research into age-related hearing impairment. Biomed Res Int 2014, 390601.

13. Bainbridge KE, Hoffman HJ \& Cowie CC (2008) Diabetes and hearing impairment in the United States: audiometric evidence from the National Health and Nutrition Examination Survey, 1999 to 2004. Ann Intern Med 149, 1-10.

14. Oron Y, Elgart K, Marom T et al. (2014) Cardiovascular risk factors as causes for hearing impairment. Audiol Neurootol 19, 256-260. 
15. Emmett SD \& West KP Jr (2015) Nutrition and hearing loss: a neglected cause and global health burden. Am J Clin Nutr 102, 987-988.

16. Le Prell CG, Gagnon PM, Bennett DC et al. (2011) Nutrientenhanced diet reduces noise-induced damage to the inner ear and hearing loss. Transl Res 158, 38-53.

17. Choi YH, Miller JM, Tucker KL et al. (2014) Antioxidant vitamins and magnesium and the risk of hearing loss in the US general population. Am J Clin Nutr 99, 148-155.

18. Curhan SG, Eavey RD, Wang $M$ et al. (2014) Fish and fatty acid consumption and the risk of hearing loss in women. Am J Clin Nutr 100, 1371-1377.

19. Durga J, Verhoef P, Anteunis LJ et al. (2007) Effects of folic acid supplementation on hearing in older adults: a randomized, controlled trial. Ann Intern Med 146, 1-9.

20. Shargorodsky J, Curhan SG, Eavey R et al. (2010) A prospective study of vitamin intake and the risk of hearing loss in men. Otolaryngol Head Neck Surg 142, 231-236.

21. Spankovich C \& Le Prell CG (2013) Healthy diets, healthy hearing: National Health and Nutrition Examination Survey, 1999-2002. Int J Audiol 52, 369-376.

22. Curhan SG, Wang M, Eavey RD et al. (2018) Adherence to healthful dietary patterns is associated with lower risk of hearing loss in women. J Nutr 148, 944-951.

23. Choi JS, Betz J, Deal J et al. (2016) A comparison of self-report and audiometric measures of hearing and their associations with functional outcomes in older adults. J Aging Health $\mathbf{2 8}$, 890-910.

24. Hu FB (2002) Dietary pattern analysis: a new direction in nutritional epidemiology. Curr Opin Lipidol 13, 3-9.

25. Martinez-Lacoba R, Pardo-Garcia I, Amo-Saus E et al. (2018) Mediterranean diet and health outcomes: a systematic meta-review. Eur J Public Health 28, 955-961.

26. Kiely KM, Gopinath B, Mitchell P et al. (2012) Evaluating a dichotomized measure of self-reported hearing loss against gold standard audiometry: prevalence estimates and age bias in a pooled national data set. J Aging Health 24, 439-458.

27. Bainbridge KE \& Wallhagen MI (2014) Hearing loss in an aging American population: extent, impact, and management. Annu Rev Public Health 35, 139-152.

28. Henderson D, Bielefeld EC, Harris KC et al. (2006) The role of oxidative stress in noise-induced hearing loss. Ear Hear 27, $1-19$.

29. Curtin LR, Mohadjer LK, Dohrmann SM et al. (2013) National Health and Nutrition Examination Survey: sample design, 2007-2010. Vital Health Stat 2 issue 160, 1-23.

30. Trichopoulou A, Costacou T, Bamia C et al. (2003) Adherence to a Mediterranean diet and survival in a Greek population. $N$ Engl J Med 348, 2599-2608.

31. National Center for Health Statistics (2011) National Health and Nutrition Examination Survey Audiometry Procedures Manual. https://www.cdc.gov/nchs/data/nhanes/nhanes_ 09_10/audiometry_09.pdf (accessed November 2018).

32. World Health Organization (2018) Grades of hearing impairment. http://www.who.int/pbd/deafness/hearing_impairment_ grades/en/ (accessed November 2018).

33. Gopinath B, Schneider J, Flood VM et al. (2014) Association between diet quality with concurrent vision and hearing impairment in older adults. J Nutr Health Aging 18, 251-256.
34. Croll PH, Voortman T, Vernooij MW et al. (2019) The association between obesity, diet quality and hearing loss in older adults. Aging (Albany NY) 11, 48-62.

35. Le Prell CG, Yamashita D, Minami SB et al. (2007) Mechanisms of noise-induced hearing loss indicate multiple methods of prevention. Hear Res 226, 22-43.

36. Partearroyo T, Vallecillo N, Pajares MA et al. (2017) Cochlear homocysteine metabolism at the crossroad of nutrition and sensorineural hearing loss. Front Mol Neurosci 10, 107.

37. Joshi R, Adhikari S, Patro BS et al. (2001) Free radical scavenging behavior of folic acid: evidence for possible antioxidant activity. Free Radic Biol Med 30, 1390-1399.

38. Sies H, Stahl W \& Sundquist AR (1992) Antioxidant functions of vitamins. Vitamins $\mathrm{E}$ and $\mathrm{C}, \beta$-carotene, and other carotenoids. Ann N Y Acad Sci 669, 7-20.

39. Fujita T, Yamashita D, Uehara N et al. (2015) A high-fat diet delays age-related hearing loss progression in C57BL/6J mice. PLoS One 10, e0117547.

40. Gopinath B, Flood VM, McMahon CM et al. (2011) Dietary antioxidant intake is associated with the prevalence but not incidence of age-related hearing loss. J Nutr Health Aging 15, 896-900.

41. Curhan SG, Stankovic KM, Eavey RD et al. (2015) Carotenoids, vitamin A, vitamin $\mathrm{C}$, vitamin $\mathrm{E}$, and folate and risk of self-reported hearing loss in women. Am J Clin Nutr 102, 1167-1175.

42. Berner B, Odum L \& Parving A (2000) Age-related hearing impairment and B vitamin status. Acta Otolaryngol 120, 633-637.

43. Michikawa T, Nishiwaki Y, Kikuchi Y et al. (2009) Serum levels of retinol and other antioxidants for hearing impairment among Japanese older adults. J Gerontol A Biol Sci Med Sci 64, 910-915.

44. Attias J, Weisz G, Almog S et al. (1994) Oral magnesium intake reduces permanent hearing loss induced by noise exposure. Am J Otolaryngol 15, 26-32.

45. Gopinath B, Flood VM, McMahon CM et al. (2010) Dietary glycemic load is a predictor of age-related hearing loss in older adults. $J$ Nutr 140, 2207-2212.

46. US Department of Agriculture, Center for Nutrition Policy and Promotion (1995) The Healthy Eating Index. https://www. fns.usda.gov/resource/healthy-eating-index-hei (accessed December 2018).

47. Fung TT, McCullough ML, Newby PK et al. (2005) Dietquality scores and plasma concentrations of markers of inflammation and endothelial dysfunction. Am J Clin Nutr 82, 163-173.

48. Park Y, Dodd KW, Kipnis V et al. (2018) Comparison of self-reported dietary intakes from the automated selfadministered 24-h recall, 4-d food records, and foodfrequency questionnaires against recovery biomarkers. Am J Clin Nutr 107, 80-93.

49. Center for Nutrition Policy and Promotion, US Department of Agriculture (2016) Healthy Mediterranean-Style Pattern - Recommended Intake Amounts. https://www. cnpp.usda.gov/sites/default/files/usda_food_patterns/Healthy Mediterranean-StylePattern-RecommendedIntakeAmounts.pdf (accessed January 2019). 